\title{
Teaching Ph.D. Students to Teach Political Science: The Emory TATTO Program*
}

\author{
H. Gibbs Knotts, Emory University \\ Eleanor C. Main, Emory University
}

Us

ntil fairly recently, political science graduate students at Emory University received little formal training before entering the classroom. This changed in the fall of 1991, when the Graduate School of Arts and Sciences inaugurated the Teaching Assistant Training and Teaching Opportunity (TATTO) program. Participation in TATTO is meant to prepare graduate students to enter the professoriate as competent and confident teachers. The ultimate goal is to ensure that each student's education as a research scholar is balanced with thoughtful and thorough preparation in the art of teaching. The creators of TATTO believed that teaching and research are complimentary, rather than conflicting, activities and that the pursuit of knowledge that lends itself to dissemination through the many varied forms of teaching is the raison d'être of college instructors.

The TATTO program emerged at Emory for several reasons. Perhaps most importantly, the creators of TATTO were responding to the increasing scrutiny of teaching at colleges and universities by legislators, parents, and the general public. Funders and consumers of higher education were demanding better teachers, and the Graduate School wanted to establish a program to prepare $\mathrm{Ph} . \mathrm{D}$. students for success in this type of market. Within

H. Gibbs Knotts is a Ph.D. candidate in the department of political science at Emory University. Having completed all five stages of the TATTO program, he is now finishing his dissertation, "Social Capital and Community Development Corporations: Vehicles for Neighborhood Revitalization."

Eleanor C. Main is associate provost of graduate studies at Emory University.
Emory, the university had just undergone ten years of enormous growth in research activity that began in 1979 following a large grant from the Emily and Ernest Woodruff Fund. With the establishment of TATTO, Emory's faculty and administration redirected time and resources to teaching. Finally, the creators of TATTO were inspired by, and borrowed from, several smaller efforts to improve teaching already underway at Emory.

Emory's program is not optional nor limited to certain students who might teach; completion is a degree requirement for all Ph.D. students. Participation in the TATTO program begins prior to a graduate students' first teaching opportunity, and the multistage process is monitored and coordinated by the Graduate School. The five stages of Emory's program are:

\section{Stage One: The Graduate School Course \\ Stage Two: The Departmental \\ Course \\ Stage Three: The Teaching Assis- \\ tantship \\ Stage Four: The Teaching Associ- ateship \\ Stage Five: The Dean's Teaching Fellowship}

Every doctoral student must participate in stages one through four, and completion of these requirements is noted on the student's transcript. Stage two takes place simultaneously with stages three, four, and five. There is a minimum requirement of at least one teaching assistantship and one teaching associateship for each participant and a maximum limit of four assistantships and/or associateships in the student's first four years. As a result, every doctoral student gains some teaching experience and no student teaches too much.
We detail the five components of Emory's TATTO program and discuss how the program has evolved within the political science department. In addition to outlining the strengths of TATTO, we identify several problems that have arisen and describe the steps that have been taken to resolve them. We conclude by suggesting which parts of TATTO could be most easily replicated at other universities.

\section{The Graduate School Course}

Political science graduate students' TATTO experience begins with the Graduate School Course. The three-and-one-half-day course takes place immediately prior to the fall term and precedes a student's first teaching experience. Students are introduced to various teaching approaches and exposed to the experience and wisdom of 50 of Emory's best faculty. The Fund for the Improvement of Post-Secondary Education (FIPSE) provided a three-year grant for development of this course and payment of modest stipends. Graduate students receive $\$ 350$ upon completing the course.

The Graduate School Course covers general topics important to students in all disciplines. Four plenary sessions address lecturing, diversity in the classroom, campus resources, and perspectives on the professoriate. In addition, there are multiple sessions of six smaller seminars covering writing, designing a syllabus, grading, voice and body, teaching using discussion, and integrating technology.

Aside from the faculty-led sessions, a seminar on "Fostering an Environment for Learning" is led by two of Emory's more senior gradu- 
ate students. Participants in these sessions analyze, discuss, and recommend actions in response to common scenarios involving teaching assistant/associate-undergraduate interactions. The scenarios are based on actual cases that have come before university mediation and disciplinary panels, and include difficulties with dating students, the challenges facing female TAs, and problems with using discriminatory rhetoric in the classroom.

The final component is the microteaching experience. Each student conducts a miniclass before a group of peers and a faculty member who offer critiques of the teaching performance. Microteaching provides a forum for graduate students to apply their newly learned skills and gain confidence before facing a classroom full of undergraduates.

Although the Graduate School Course gives TAs a solid base of general information about teaching, it cannot prepare them for the uniquely difficult questions and situations that inevitably arise in an actual classroom. Similarly, graduate students may be teaching their own class as teaching associates for up to three years after taking the Graduate School Course. Consequently, TATTO participants are required to receive training that directly coincides with classroom teaching.

\section{The Departmental Course}

In this second stage, political science graduate students receive discipline-specific training. The Departmental Course meets 12-13 times over two semesters, and meetings usually last about an hour. Stu- dents normally take the course during their third year in the program, when most will also serve as teaching assistants and teaching associates. Faculty members in the department lead each of the sessions and topics vary from year to year, according to graduate student feedback. During the first semester, the topics typically include teaching and political science as a career, promoting class discussion, promoting student writing, lecturing, testing and evaluation, maintaining good faculty/ student relations, and dealing with gender issues. Second semester topics include meeting the challenges and dilemmas of teaching introductory courses, developing a syllabus, helping students draw fact/value distinctions, using simulations in the classroom, teaching "methods," and teaching graduate seminars. Both semesters usually end with a microteaching session in which participants view and critique videotapes of volunteers' classes. Recently, classes have been added on the use of computers in the classroom, integrating community service into syllabi, dealing with complaints about grades, and what to do when you run out of material before the bell rings.

According to participants, the Departmental Course has been quite helpful. A number have noted that they appreciated the discussions on how to integrate theory into lectures and the difficulty of doing so when teaching a course outside of one's major field. In addition, several students have emphasized their appreciation of the faculty's willingness to acknowledge the difficulties and disasters that sometimes occur while teaching. Some students thought that faculty in the Graduate School Course tended to gloss over these difficulties and offer potential solutions that were too "easy," tending to emphasize simply "drawing boundaries" and being "professional." The willingness of departmental faculty to acknowledge problems seems to have provided students with some assurance that it is okay to stumble and take chances.

Conversations with graduate students and faculty members assure us that the Departmental Course is making a difference. The sessions provide a regular forum for graduate students and faculty to discuss the challenges of teaching. Most importantly, the discussions arise from the actual experiences of graduate student teachers. This means problems can be addressed while they are happening. Finally, the Departmental Course has encouraged graduate students to be conscious of what they want to get out of an academic career. Experiences in the TATTO program have forced the students to evaluate and discuss the balance between teaching and research, which have often guided students toward the type of academic environment in which they would be most satisfied.

\section{The Teaching Assistantship}

In the political science department, most graduate students meet their TATTO Teaching Assistant requirement by serving as a TA for an introductory American government class. These TAs meet weekly with three discussion sections, which usually have between 10-15 students. TAs are responsible for assigning grades to all of the students in their sections.

Teaching assistants receive feedback and support in a number of ways. First, the supervising faculty holds weekly meetings with all of the TAs for her course. Second, the supervising faculty attends one of each TAs' sections, and completes a written evaluation of the TA's teaching performance. Third, TAs attend the Departmental Course, in which they get a chance to discuss issues that arise in the classroom. Fourth, the students in each section evaluate teaching performance of their TA using TATTO-designed forms. Finally, TAs write personal assessments. 
The biggest challenge in this stage of TATTO is ensuring that faculty members provide consistent, constructive evaluations of students' teaching. TATTO organizers originally developed a number of evaluation forms modeled on those used by other institutions. While these forms provide some useful guidelines for evaluation, they are rarely used by departmental faculty. Furthermore, it is not uncommon for a faculty member to have four or five teaching assistants, and the recommended evaluation process places considerable time demands on this individual.

The political science department's TATTO coordinator is taking several steps to increase the likelihood that graduate students are formally evaluated. Rather than relying on a single faculty member to observe every $\mathrm{TA}$, beginning next year faculty evaluators will be drawn from the entire department. Also, graduate students are being made formally responsible for approaching faculty to schedule observations.

Fifth-year funding decisions are based largely on the strength of the evaluations received by graduate students. Therefore, if observations do not take place, graduate students will be at a disadvantage in competing for a Dean's Teaching Fellowship, the final stage of the TATTO program.

\section{The Teaching Associafeship}

As a Teaching Associate a graduate student has the opportunity to coteach an entire course with a faculty member. Graduate students in political science may elect to coteach a course of their choosing, collaborating with the faculty member in all aspects of the course.

As in the earlier stages of TATTO, teaching associates receive considerable feedback. They meet regularly with their supervising faculty member to discuss course issues. They also attend the Departmental Course. The supervising faculty member writes a formal evaluation of the teaching associate, who is also evaluated by her students. In addition, the teaching associate must complete a personal evaluation of her performance in the classroom.

Although there have been a number of exceptional coteaching experiences in the political science department, this is perhaps the stage of the program where the most problems have arisen. One of the biggest concerns for faculty is the amount of work required to mentor the associates. Some find the experience quite burdensome. In addition, both faculty members and graduate students have argued that having, in effect, two instructors can result in a weaker class. This is not because graduate students are not good teachers, but rather because having two instructors can disrupt the flow and rhythm of the class.

Despite these difficulties, continued dialogue among faculty and graduate students has yielded a number of suggestions for improving the coteaching experience. In general, coteaching appears to be much more successful when the supervising faculty member makes the status of the teaching associate immediately clear to the class. Also, the associates appear to have more success when they teach several successive sessions. This schedule allows the graduate student to develop a rhythm and make corrections quickly. It also reduces the pressure on the faculty member to correct the graduate student during a class session. Experience further suggests that faculty and graduate students should review the associate's lecture notes in advance with an eye to possible questions. When inaccuracies do surface, the faculty member needs to realize that they do not have to be corrected immediately. Mistakes, misstatements, and malapropisms can be addressed after the class session, enabling the associate to make corrections during his next lecture. Also, faculty and graduate students should anticipate differences in grading and take mea- sures like cooperatively developing tests and grading keys to minimize potential conflicts. Perhaps the most important condition for success is that the supervising faculty member and associate meet on a regular basis. Despite the time commitment, regular meetings and open communication seem to be the best assurance of a beneficial experience for everyone involved in the process.

\section{The Dean's Teaching Fellowship}

In 1993, the Graduate School established a fifth stage in the TATTO program, the Dean's Teaching Fellowship, to recognize graduate students who have demonstrated exceptional ability in and dedication to teaching. This teaching fellowship, awarded annually by an Emory faculty committee, provides 32 graduate students with one year of funding beyond the four for which most are eligible. Teaching fellows are completely responsible for teaching one course each semester. They design a syllabus, select readings, evaluate students' performance, and assign grades.

In the political science department, graduate students interested in a Dean's Teaching Fellowship submit applications to the department in early January of their fourth year of study. Applications must include sample syllabi and a statement of the applicants' teaching goals and philosophy. Students usually ask to teach one lower-level course and one more advanced course, the latter usually being related to the student's dissertation topic. A departmental committee writes letters of support based upon application materials, teaching evaluations, and the progress of the applicant toward completion of her dissertation. In 1998-99, three political science graduate students held teaching fellowships. 


\section{Concluon: Taking Teaching Seriously}

Emory's TATTO program utilizes the resources of the entire university to teach graduate students how to teach. For this reason, it may be impractical for a single department head or faculty member to attempt to institute a program on the scale of Emory's. Given more limited resources or moderate faculty interest, what aspects of Emory's program are worth replicating? First, every political science department would benefit from establishing some type of departmental teaching course. This course provides a regular forum for graduate students and faculty to talk and think about teaching. Second, when possible, political science departments should reward excellence in graduate student teaching by giving the best TAs chances to teach their own courses. Formalizing this process creates a competitive environment and provides structured incentives for faculty and graduate students to take teaching more seriously.

\section{Note}

* A previous version of this article was presented at the American Political Science Association convention in August 1997. We would like to thank our colleagues Richard Doner and Randall Strahan for their helpful suggestions.

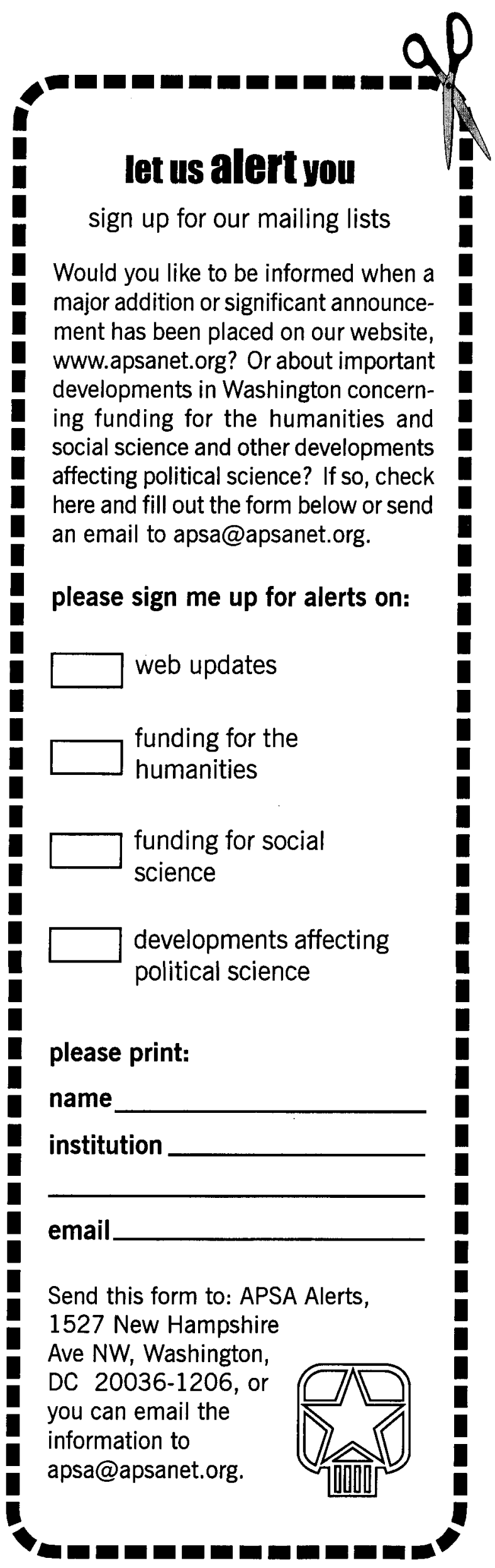

